\title{
RELATIONSHIP BETWEEN EMOTIONAL INTELLIGENCE AND LEVELS OF DEPRESSION AMONG PATIENTS WITH DEPRESSIVE DISORDERS. \\ ${ }^{1}$ Mohamed Ali Abdelsattar Zoromba, ${ }^{2}$ Sayeda Ahmed Abdellatif , ${ }^{3}$ Elsayed Saleh Hussien \& 4 Warda El-shahat Hamed \\ 1,4 Psychiatric and mental health Nursing, Faculty of Nursing, Mansoura University, 2 Psychiatric and mental health Nursing, Faculty of Nursing, Cairo University. 3 Psychiatric Mental Health, Faculty of Medicine, Mansoura University, E-mail of the corresponding author: zromba2010@gmail.com
}

\begin{abstract}
The study aims to assess the relationship between emotional intelligence and levels of depression among patients with depressive disorders. A descriptive correlational study was utilized with a sample of (106) depressed patients who were diagnosed by a psychiatrist with depressive disorders and attend outpatient clinics in Mansoura University Hospitals. Data were collected by using three tools, one for assessing socio demographic characteristics which developed by the investigator, and the second for assessing level of depression using Beck Depression Inventory BDI-II, and the third for assessing emotional intelligence using Barchard emotional intelligence questionnaire. Results revealed a varied, significant negative correlation between level of depression and positive expressivity, attending emotion, responsive joy, emotion and decision making and empathetic concern. In conclusion, there is a highly significant relationship between the level of depression and emotional intelligence. Therefore, it is recommended to use the emotional intelligence in preventing and managing depression.
\end{abstract}

Keywords: Emotional Intelligence, Level Of Depression, Depressive Disorders.

\section{Introduction:}

Emotional intelligence is considered essential for one's physical health and psychological adaptation. Emotional intelligence is a potential risk factor or protective factor in mental and physical health, especially in cases of depression ${ }^{[1]}$. The inverse relationship between different measures of emotional intelligence and depression has been supported by researchers working in the field of emotional intelligence ${ }^{[2]}$.

Emotional Intelligence is broadly defined as a set of abilities concerned with the regulation, management, control and use of emotions in decision-making, particularly in relation to the promotion of healthy and adaptive mental functioning. Emotional intelligence offers a window into mental health, as the ability of individuals to understand their own emotional states or emotional problems so it is considered an important indicator of healthy mental functioning ${ }^{[1]}$.

Emotional intelligence was considered as a set of skills for processing emotional information and using this information to guide one's thinking and actions. Since then, various theoretical approaches have attempted to explain emotional intelligence.

Emotional intelligence has five elements; self-awareness, self-regulation, motivation, empathy and social competences. Self-awareness is the ability to recognize and understand one's emotions, moods, and drives as well as how these impact on others. Selfregulation is the ability to control any 
disruptive emotions or responses. Motivation refers to a drive to work toward a common goal. Empathy involves the ability to understand and accept other's emotions, moods, and drives. Social skills refer to the ability to manage relationships and networks with others through finding common ground ${ }^{[3]}$.

Teaching individuals how to perceive their emotions to facilitate thought, to understand their emotions, to give meaning to their emotional experiences, and to regulate their emotions it may be possible for them to manage their emotions more positively, preventing depression to enter their lives ${ }^{[4],[5] \&[6]}$.

The existence of reliable predictors of who is most likely to suffer from depression would represent a valuable step towards the development of prophylactic strategies for protecting individuals prior to disease onset as well as providing a curative method for depressed patients to alleviate their depression. The emerging construct of emotional intelligence may constitute such a predictor ${ }^{[7]}$.

Depression; the most common of the affective disorders characterized by persistent sad mood, anxiety, anhedonia and irritability. Depressive disorders affect a person's thoughts, feelings, physical, and social relationships with the whole person being in effect. In spite of its enormous importance, depression often goes undetected or it is not suitably treated. This results in suffering and a lower quality of life for those affected as well as, their family members and all society ${ }^{[1]}$.

Depression is rated (by the World Health Organization) as the $4^{\text {th }}$ largest cause of global disease burden in terms of its impact on the individual, family and society in general, it is estimated to be the $2^{\text {nd }}$ leading contributor to the global burden of disease by the year 2020 that lead to less productivity. Depression is common, affecting about 340 million people worldwide. Depression is projected to become the leading cause of disability. Depression occurs in persons of all genders, ages, and backgrounds ${ }^{[8]}$.

There are different levels of depressive disorders; major depressive disorder, or major depression, is characterized by a combination of symptoms that interfere with a person's ability to work, sleep, study, eat, and enjoy once-pleasurable activities. Major depression is disabling and preventing a person from functioning normally. Dysthymic disorder, or dysthymia, is characterized by long-term (2 years or longer) symptoms that may not be severe enough to disable a person but can prevent normal functioning or feeling well. Minor depression is characterized by having symptoms for 2 weeks or longer that do not meet full criteria for major depression ${ }^{[9]}$.

Depression, a treatable disorder, is often treated with pharmacological therapies that have shown to have inconsistent effects and can have devastating side effects. Nonpharmacological approaches, such as cognitive behavioral therapy (CBT) and interpersonal therapy (IPT) are often used to treat depression. Using Cognitive Behavioral Therapy (CBT), interpersonal therapy (IPT) and new coping skills are taught to help in alleviating the symptoms of depression. As well as using electroconvulsive therapy (ECT) for patients not responding to pharmacotherapy or psychotherapy is effective ${ }^{[10]}$.

\section{Aim of the study:}

The aim of this study was to recognize the relationship between emotional intelligence and levels of depression among patients with depressive disorders.

\section{Subjects and Method:}

\section{Study Design:}

A descriptive research design was used to conduct the current study. 
Setting:

The study was carried out in the outpatient clinic of Psychiatric Department of Mansoura University Hospital.

\section{Subjects:}

Convenient sample of 106 patients (both sexes and all age groups were included) attending the out-patient clinic of Psychiatric Department of Mansoura University Hospital diagnosed by psychiatrist as having depressive disorders according DSM-IV TR from beginning of December 2013 to the end of March 2014. Exclusion criteria:

1- Patients with depression related to substance abuse.

2- Patients with depression related to organic disease.

Tools: Three tools was used to collect data, includes: Tool I: SocioDemographic and clinical history. Tool II: Arabic version of Beck Depression Inventory (BDI-II) was used it contains 21 items; the response was measured on a four value scale ranging from 0 to 3 . This tool was translated into Arabic by Ghareeb $^{[11]}$. Tool III: Emotional Intelligence scales: These scales were originally developed by (Barchard, 2001) $[12]$ to assess the level of emotional intelligence, it consists of 68 items, using 5 point Likert scale, the tool was translated to Arabic. Reliability done using Cronbach's Alpha test equaled 0.67.

\section{Pilot study:}

The pilot study was carried out on 15 patients and these patients didn't included in the actual study to test the clarity and applicability of the tool.

\section{Filed work:}

The actual study was conducted during the period from beginning of December 2013 to the end of March 2014.

\section{Ethical consideration:}

- The permission was obtained from the faculty of nursing ethics committee.

- Verbal or informed consent of the patient was obtained

\section{Statistical analysis:}

Data were analyzed using SPSS version 16. The normality of data was first tested with one-sample Kolmogorov-Smirnov test. Qualitative data were described using number and percent. Pearson correlation used for correlation between continuous parametric data while spearman correlation to correlate between continuous non- parametric data. The significance is fixed at $5 \%$ level ( $p$-value).

Results:

Table (1) shows that $(57.7 \%)$ aged from twenty to forty years, (33\%) aged from forty one to sixty. Females represent (58.5\%) 62 patients where males represent $(41.5 \%) 44$ patients of the sample, $(52.2 \%)$ of patients lives in rural, while $(47.1 \%)$ of patients lives in urban. Marital statuses of studied sample; (33\%) are singles and about (57\%) are married. Table reveals that $(36.8 \%)$ obtained secondary education, $(22.6 \%)$ graduated from university where $(28.3 \%)$ of patients with fundamental education. As the table present that $(43 \%)$ working in contrast $(12 \%)$ without work while about $(30 \%)$ are house wives. 
Mohamed Ali Abdelsattar Zoromba et. al.

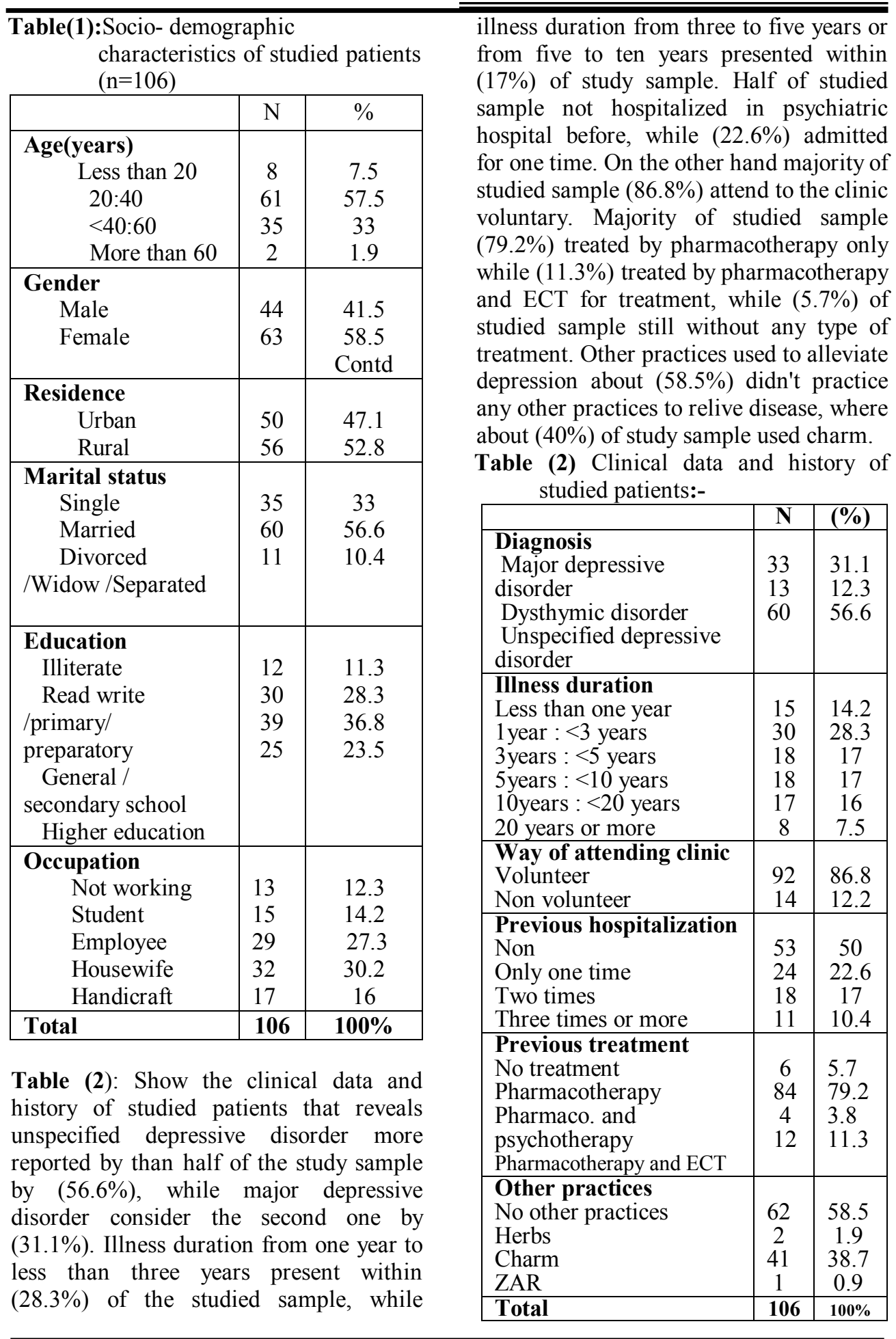


RELATIONSHIP BETWEEN EMOTIONAL INTELLIGENCE etc...

Table (3) delineates the correlation between depression level and sub scale of emotional intelligence that there is highly statistically significant negative correlation between depression score and positive expressivity, attending emotion, responsive joy and empathetic concern where $\mathrm{r}=-.5,-.504,-.515$ and -.363 at $\mathrm{p}=.001, .001, .001$ and .001 respectively, this correlation is weak with empathetic concern. There is a weak significant negative correlation between depression score and emotion and decision making. On the other hand, there is no statistical significant correlation between depression score related to negative expressivity and responsive distress. There is highly statistically significant negative correlation between depression level and emotional intelligence where $r=-0.651$ at $\mathrm{p}=0.001$ that's reveal a mild reverse relationship.

Table (3): correlation between depression level and sub scale of emotional intelligence.

\begin{tabular}{|l|c|c|}
\hline Item & $\mathrm{R}$ & $\mathrm{P}$ \\
\hline $\begin{array}{l}\text { Positive } \\
\text { expressivity }\end{array}$ & -0.5 & $\leq 0.001^{*}$ \\
\hline $\begin{array}{l}\text { Negative } \\
\text { expressivity }\end{array}$ & 0.065 & 0.51 \\
\hline $\begin{array}{l}\text { Attending \& } \\
\text { emotion }\end{array}$ & -0.504 & $\leq 0.001^{*}$ \\
\hline $\begin{array}{l}\text { Emotion } \\
\text { decision making }\end{array}$ & -0.226 & $0.02^{*}$ \\
\hline Responsive joy & -0.515 & $\leq 0.001^{*}$ \\
\hline Responsive distress & 0.082 & 0.406 \\
\hline Empathetic concern & -0.363 & $\leq 0.001^{*}$ \\
\hline \multicolumn{1}{|c|}{ Total } & -0.651 & $\leq 0.001^{*}$ \\
\hline
\end{tabular}

\section{Discussion:}

Concerning biological profile the results of this study demonstrate that there is more than half of the studied sample was females. This findings are congruent with studies in different countries. For instance, females in Egypt had a higher ratio for depression. Researches in Pakistan, United
States, Turkey and Spain found that females outnumbered males in the prevalence of depression ${ }^{[13]-[20]}$.

This finding may be related as females get depression more than males for many different causes like hormonal changes; menstruation and menopause related to mood disorders. Premenstrual dysphoric disorder is a type of depressive disorders related to menstruation. Added to that estrogen and progesterone may affect the nervous system. Another cause for gender differences may be due to the social system; girls may be limited in their social system within more family precautions and may be dependent on their families. On the other hand boys have been encouraged to develop a large social system, sense of mastery and independence in their lives.

Gender differences in coping style may be another cause of an increased ratio of depression among females; women tend to use emotions to overcome problems, while men tend to use the mind. Also, our culture inhibits female's expression of aggression, this aggression is usually turned inward and it appears in the form of losing interest. Differences in frequency of and reaction to stressful life events consider an important other cause of an increased ratio of depression among females; women experience more stressful life events and have a greater sensitivity to them than men. Social roles of women consider other cause; women are responsible for children, housing and reproduction. Women also may have a work, all of this is social roles affecting their feeling of interest and leading to depression.

As regards age factor, results reveal that more than half of depressive patients were young aged between 20:40 years. One third of the studied sample was adults aged 41:60 years. The mean age for depression was 22.9 years. Results indicate that the diagnosis of depression tended to be more frequent among those who aged 20:40 years. 
These results are very important and serious results, it's not affecting patients life's or his relatives only, and it may adversely affect the whole of society. Age of working, goal achievement and productivity is the most age risk for depression.

The increasing prevalence of depression at the age of early adulthood may be related to inappropriateness marital family interaction and increased life stressors. Young adults may have-not the awareness for how to live the life. Young adults are now responsible for daily duties toward family and work, life becomes more difficult and our country undergoing a serious period affecting people's life stressfully.

Regarding educational level of studied sample two fifth of depressive patients with middle, secondary education, while one quarter of the studied sample have highly education, this may be related to increased prevalence of depression for those who aged less than 20 up to 40 years. One third of depressive patients are illiterate or with fundamental education.

Depression affects anyone with different educational level, regardless this level as the causes of depression include factors as: genetic, biological, neurochemical and psychological or sociological factors which didn't show any importance for education or culture.

Despite the findings of other practices used by patient to overcome their depression, more than half of studied sample said that they didn't practice other popular practices to overcome depression, on the other hand, two fifth of patients used charm, only two patients used herbs and only one patient used "ZAR".

In relation to emotional expression it was founded that the mean level of understanding the emotional knowledge and the ability to express emotions nonverbally in situations, the current study found that expression of positive emotions correlates significantly and negatively to depression score. Previous studies found a significant negative correlation between score of depression and emotional expression; clinically depressed patients scored lower on the emotional intelligence dimension's emotional expression ${ }^{[1]} \&[21]$. Significant negative correlations was found between depression and the comprehension of emotion ${ }^{[17]}$.

These results may be related to the nature of depressed patients who express negative thoughts toward everything and they can't express any positive thoughts or emotions. Depressed patients can't laugh out loud if something is funny, can't express happiness, find it difficult to hug close friends, have difficulty showing people that they care about them, shout or scream when they are angry and may they keep his happy feelings to themselves.

Regarding responsive joy that means tendency to become cheerful in the presence of other people who are cheerful and responsive distress that mean tendency to become distressed in the presence of another people who are distressed, current study finds that responsive joy correlate significantly and negatively to depression score.

Comparing with previous studies; a significant negative correlation was found between levels of depression and understanding other's emotions, clinically depressed patients scored lower on the understanding other's emotions subscale of emotional intelligence ${ }^{[21]}$. Significant negative correlations was found between late life depression and ability to accurately identify emotion in oneself and others ${ }^{[17]}$. Different studies also found that interpersonal subscale of emotional intelligence demonstrate a significant negative correlation to depression ${ }^{[22],[15] \&}$ [23].

Regarding attending to emotion which means the ability to attend emotions to be aware of them; current results reveal a 
significant negative correlation between score of depression and attending to emotion this result is consistent with other studies that found a significant negative correlations between the emotional recognition and depression score, depressed group scored lower than the control group on an emotional recognition sub scale of emotional intelligence ${ }^{[1],[16] \&}$ [21].

From the investigator's point of view, results may be related to deterioration of affect and intellect of depressed patients as they unable to identify emotion in themselves and others, leading to inability to attend emotions and to be aware of them. Attending emotions are the emotional intelligence component that refers to using the intellect in normalizing and regulating one's emotion. Patients with higher depression score were unable to attend their emotion into their awareness and intellectual functions.

Regarding empathy the current results reveal a significant negative correlation between empathy and depression score. This result supported different studies which found that depression correlate negatively with empathy "the emotional intelligence component", higher level of empathy related to low depression score [15], [23] \& [24]

Regarding emotion and decision making current study reveal that there is a significant negative correlation between emotion and decision making to level of depression. Other studies found that the correlation between emotional intelligence component; facilitating thought are not significant with depression ${ }^{[25], \text { [26] \& [17] }}$.

For the correlations between emotional intelligence score and depression level of studied sample, the results showed that there is a highly statistical significant negative correlation between emotional intelligence score and depression score. Current result congruent with others who found that total emotional intelligence showed inverse significant correlation with depression, results indicate that emotional intelligence significantly predicts depression ${ }^{[15] \&[17]}$. Other studies support the significant negative correlation between total emotional intelligence score and depression score ${ }^{[21]},[27] \&[26]$. Moreover, there was a study found that depressive symptoms decreased significantly with a group received training involved emotional intelligence skill training greater than the other depressed group not receive the training ${ }^{[28]}$.

The negative correlation between emotional intelligence and depression may be related to the emotional intelligence skill which is the skill of social and emotional capacities which stem from knowledge based on feelings and the deterioration of feelings directly affect this skill. Depression expresses pessimism, negative emotions, and the dissatisfaction with life. Therefore, whenever an individual emotional intelligence is high, he possesses a greater capacity in overcoming the feelings of depression.

\section{Recommendation:}

Based on the findings of the current study, the following recommendations are:

1-Implement emotional intelligence assessment methods in early detection and prevention of depression.

2- Integrate programs based on emotional intelligence in psychotherapy for managing depression.

3- Conduct a periodical workshop for adolescents and young in universities, schools, social clubs, camps and youth organizations to enhance their emotional intelligence in order to prevent depression.

4- A psychologists and counselors should be assigned to each school to assess and identify adolescents lower in emotional intelligence as they at risk for depression. 
5- Make an interpretation of why plenty of psychiatric patients look for other practices to overcome their problems.

6- Implement further studies to assess the effect of emotional intelligence programs and courses on managing depression and other psychiatric disorders

References:

1. Downey, L., Johnston, P., Hansen, K., et al. The relationship between emotional intelligence and depression in a clinical sample. The European Journal of Psychiatry, 22, 93-98; 2008.

2. Tsaousis, I., \& Nikolaou, I. Exploring the relationship of intelligence with physical and psychological health functioning. Journal of stress and Health, 21, 7786.

http://dx.doi.org/10.1002/smi.1042; 2005.

3. Cox, C. L., Hill, M. C., \& Lack, V.M. Advanced practice in health care: Skills for nurses and allied health professionals. USA, Canada: Routledge; 2012.

4. Mayer, J. D., Roberts, R. D., \& Barsade, S. G. Human abilities: emotional intelligence. Annual Review of Psychology, 59, 507-536. http://dx.doi.org/10.1146/annurev.ps ych.59.1030 0 6.093646; 2008.

5. Brackett, M.A., Rivers, S.E., \& Salovey, P. Emotional intelligence: implications for personal, social, academic, and workplace success.

Social and Personality Psychology

Compass, 5(1), $88 \quad$ e 103.

http://dx.doi.org/10.1111/j.1751-

9004.2010.00334.x/abstract; 2011.

6. Resurreccion, D.M. Salguero, J.M. \& Ruiz-Aranda, D. Emotional intelligence and psychological maladjustment in adolescence: A systematic review, Journal of Adolescence 37, 461- 472, Published by

Elsevier.

http://dx.doi.org/10.1016/j.adolescence $.2014 .03 .012 ; 2014$.

7. Ciarrochi, J., Dean, F. P., \& Anderson, S. Emotional intelligence moderates the relationship between stress and mental health. Personality and Individual Differences, 32(2), 197 - 209; 2002.

8. World Health Organization: Health statistics and health information systems. Retrieved December 12, 2012, from http://www.who.int ; 2012.

9. National Institute of Health (NIMH): depression, available at : http://nihseniorhealth.gov/depression.h tml; 2012.

10. Lloyd S. J. Emotional Intelligence: A Predictor for Depression as Related to Coping Skills in Older Adults, Published thesis, USA: ProQuest LLC; 2011. 
11. Ghareeb A. G. The Complete Norm Tables and Cut-off scores of the Beck Depression Inventory - II for Egyptian samples of both sexes: High schools, Universities, Adults, and Psychiatric patients. Cairo, Anglo American library; 2000.

12. Barchard, K. A. Emotional and social intelligence :examining its place in the nomological network. Un published thesis, faculty of graduate studies, University of British Columbia; 2001.

13. Ghanem, M., Gadallah, M., Meky, F.A., et al., National Survey of Prevalence of Mental Disorders in Egypt: preliminary survey, E M H J, 15 (1), published by WHO. Available at http://www.docstoc.com/docs. ; 2009.

14. Afifi, M. Depression in adolescents: gender differences in Oman and Egypt, Eastern Mediterranean Health Journal, 12(1), 13-15. Available

http://apps.who.int/iris/bitstream ;2006.

15. Batool, S.S., \& Khalid, R. Low emotional intelligence: a risk factor for depression. Journal of Pakistan Psychiatric Society, 6(2), 65-72.; 2009.

16. Broquard, A. G., Collage Student Mental Health: The Relationship
Between Depression and Emotional Intelligence Using the Student Relationships Assessment. Published thesis, Taylor University. Available at www.proquest.com ; 2011.

17. Inglese, $P$. Emotional Intelligence as a Predictor of Late Life Depression in Independent Older Adults. Published thesis, Walden University. Available at www.proquest.com ; 2012.

18. Lloyd S. J. , Ahmadi M. M. , Barclay K. , et al. Emotional intelligence as a predictor of depression status in older adults. Journal of Archives of Gerontology and Geriatrics, 55, 570-573. Elsevier Ireland Ltd, available at www.ScienceDirect.com; 2012.

19. Onur E, Sheridan M.J, Fukunishi I, Wise T.N. The Revised Emotional Intelligence Scale: cross cultural validation in a Turkish psychiatric outpatient cohort. Yeni Symposium 50:51-54; 2012.

20. Herrero, A., Tomás-Sábado, J. \& Gómez-Benito, J. (2014). Associations between emotional intelligence, depression and suicide risk in nursing students. Nurse Education Today, 34, 520 - 525. available at http://dx.doi.org/1 $\underline{0.1016 / j . n e d t .2013 .07 .001}$. 
21. Nolidin, k., Downey, L. A., Hansen, K. \& Stoug, C. Associations Between Social Anxiety and Emotional Intelligence Within Clinically Depressed Patients. Psychiatry Q, 84, 513-521. Published by Springer. DOI 10.1007/s11126-013-9263-5; 2013.

22. Lamanna, M. D. The Relationships Among Emotional Intelligence, Locus of Control and Depression in Selected Cohorts of Women: Temple University; 2000.

23. Ballureka, N. Emotional intelligence and depressed mood in adolescence: A multilevel approach. International Journal of Clinical and Health Psychology 13, 110-117. Published by Elsevier España; 2013.

24. Schreiter, S., Pijnenborg, G. H. \& Ro, M. Empathy in adults with clinical or subclinical depressive symptoms, Journal of Affective Disorders, 150(1), 1-16, Elsevier; 2013.

25. Murphy, K.RA critique of emotional intelligence. New Jersey Lawrence Erlbaum Associates, inc, p19-37. ; 2006.
26. Hansenne M, Bianchi J. Emotional intelligence and personality in major depression: Trait versus state effects. Psychiatry Research 166(1):63-68; 2009.

27. Sulaiman, S. M. A. Emotional Intelligence, Depression and Psychological Adjustment among University Students in the Sultanate of Oman. International Journal of Psychological Studies; 5, (3), Published by Canadian Center of Science and Education. Available online at www.ccsenet.org/ijps; 2013.

28. Jahangard, L., Haghighi, M. Bajoghli, H., Ahmadpanah, M., Ghaleiha, A., Zarrabian, M.K., \& Brand, S. Jahangard. Training emotional intelligence improves both emotional intelligence and depressive symptoms in inpatients with borderline personality disorder and depression, International Journal of Psychiatry in Clinical Practice, 16, pp. 197-204. available at http://informahealthcare.com/doi/abs/1 0.3109/13651501.2012.6874542012 